\title{
ESTUDO DA VIABILIDADE DO ÓLEO DE PEIXE PARA PRODUÇÃO DE BIODIESEL
}

\author{
I.Y.ASANOME, L. C. CARDOSO, N. C. PEREIRA \\ Universidade Estadual de Maringá, Departamento de Engenharia Química \\ E-mail para contato: isabelaasanome@gmail.com
}

\begin{abstract}
RESUMO - Devido às constantes mudanças climáticas e ao uso descontrolado de combustíveis fósseis tem-se buscado fontes alternativas para substituir o petróleo. O biodiesel é um combustível alternativo que pode substituir total ou parcialmente o diesel, ele é produzido a partir de óleos vegetais e rejeitos gordurosos. Neste trabalho foi avaliada a viabilidade da utilização do óleo de peixe para a produção de biodiesel, por meio da reação de transesterificação etílica, utilizando catálise básica. Para isso, foram analisadas as principais características físico-químicas do óleo de peixe. Foram determinados: o índice de acidez, a massa específica, a viscosidade, o índice de iodo, o teor de umidade, o índice de saponificação e a composição em ácidos graxos deste óleo. Devido ao alto índice de acidez foi realizada a neutralização do óleo, seguida pela produção do biodiesel nas seguintes condições: temperatura de $54{ }^{\circ} \mathrm{C}$, razão molar etanol/ácido graxo de 1 : 11,79 e $0,7 \%$ de catalisador alcalino. Finalmente foi realizada a quantificação de ésteres etílicos. As propriedades do biodiesel produzido atendem aos padrões exigidos pela ANP e o óleo mostrou-se apto para a produção de biodiesel.
\end{abstract}

\section{INTRODUÇÃO}

O aumento da demanda de combustíveis, a restrição das ofertas de petróleo e o aumento da poluição, que prejudica a saúde humana e o agravamento do efeito estufa, sugerem a busca por fontes alternativas de energia. O biocombustível, em especial o biodiesel, torna-se uma alternativa para a diminuição do uso de combustíveis fósseis, reduzindo a dependência de importação de petróleo. O biodiesel é um combustível biodegradável constituído de uma mistura de ésteres alquílicos de ácidos carboxílicos de cadeia longa, produzido a partir de óleos vegetais, gordura animal, óleos e gorduras residuais e é miscível com o diesel de petróleo em qualquer proporção (KNOTHE et al., 2006).

O óleo de peixe é uma matéria-prima alternativa para a produção do biodiesel por ser extraído do conteúdo de lipídios das partes rejeitadas do peixe. De acordo com a Organização das Nações Unidas para Alimentação e Agricultura, a produção mundial de peixes em 2015 foi de 166,8 milhões de toneladas de peixes e estima-se que produção da pesca e aquicultura no Brasil deve crescer mais de $100 \%$ até 2025.

O biodiesel proveniente de rejeitos gordurosos, tais como vísceras de peixe, é ambientalmente e economicamente mais vantajoso que o obtido a partir do óleo vegetal por não competir com a alimentação humana e aproveitar um resíduo usualmente descartado no meio ambiente. Além disso, gera uma alternativa de renda para a piscicultura local, por meio 
dessa matéria-prima de alta produtividade e baixo custo, minimizando os impactos ambientais (BERY et al., 2012). Ainda, permite um abastecimento contínuo, fato que não é possível com oleaginosas, devido à sua produção sazonal.

Este trabalho teve como objetivo estudar a viabilidade do óleo de peixe para sintetizar, pela reação de transesterificação via catálise básica, ésteres etílicos. Para tanto foi realizada a caracterização físico-química do óleo de peixe e a produção do biodiesel etílico.

\section{MATERIAIS E MÉTODOS}

\subsection{Matéria-Prima}

O óleo de peixe utilizado para a produção de ésteres etílicos foi adquirido da empresa Aboissa Óleos Vegetais da cidade de São Paulo - SP, Brasil. Este óleo foi originado de resíduos de peixes marinhos, tais como a sardinha, atum e o salmão. O reagente foi o etanol anidro e o catalisador, hidróxido de sódio.

\subsection{Preparação e Caracterização da Matéria-Prima}

O óleo de peixe foi neutralizado utilizando uma solução de $\mathrm{NaOH} \mathrm{7,2} \mathrm{mol/L,} \mathrm{pelo}$ método de Zumach et al. (2012). Foram realizadas algumas análises para a caracterização do óleo de peixe. $O$ teor de ésteres foi determinado em um cromatógrafo a gás, marca Thermo Scientific, modelo Trage GC Ultra, com uma coluna da marca SGE Analytical Science, modelo BPX 70. O teor de umidade foi feito no aparelho Volumetric Karl Fisher marca Orion, modelo AF8. O índice de saponificação, o índice de acidez e o índice de iodo foram realizados de acordo com as normas AOCS Cd 3-52, AOAC 948-28 e AOAC 920.159, respectivamente. A determinação da massa específica foi realizada no densímetro, marca Anton Paar, modelo DMA 5000. Por fim, para a análise da viscosidade cinemática, foi utilizado um reômetro digital Brookfield modelo DV-III.

\subsection{Produção de Biodiesel}

A reação foi conduzida em um balão de três bocas a $54{ }^{\circ} \mathrm{C}$, com razão molar $1: 11,79$ (óleo:etanol) e 0,7\% em massa do catalisador $\mathrm{NaOH}$, com agitação a $350 \mathrm{rpm}$ por noventa minutos. Após a reação de transesterificação, foi realizada a lavagem dos ésteres etílicos pela metodologia de Geris et al. (2007).

O teor de glicerol livre, que foi determinado por meio de uma metodologia modificada, com base no método oficial da AOCS (Ca 14-56), para análise de glicerol livre em óleos e gorduras, sugerida por Dantas (2006).

\section{RESULTADOS}

\subsection{Caracterização da Matéria-Prima}

As características físico-químicas do óleo de peixe, determinadas neste trabalho, antes e após a neutralização, estão apresentadas na Tabela 1. 
Tabela 1 - Características físico-químicas do óleo de peixe

\begin{tabular}{|c|c|c|}
\hline \multicolumn{3}{|c|}{ VALORES OBTIDOS (Média \pm Desvio Padrão) } \\
\hline PARÂMETROS & $\begin{array}{c}\text { ANTES DA } \\
\text { NEUTRALIZAÇÃo }\end{array}$ & $\begin{array}{c}\text { APÓS A } \\
\text { NEUTRALIZAÇÃo }\end{array}$ \\
\hline Índice de Acidez $(\mathrm{mg} \mathrm{KOH} / \mathrm{g})$ & $10,86 \pm 0,05$ & $0,68 \pm 0,01$ \\
\hline Massa Específica $20^{\circ} \mathrm{C}\left(\mathrm{kg} \cdot \mathrm{m}^{3}\right)$ & $931,00 \pm 0,14$ & $923,00 \pm 0,17$ \\
\hline Viscosidade $40^{\circ} \mathrm{C}\left(\mathrm{mm}^{2} / \mathrm{s}\right)$ & $27,25 \pm 1,12$ & $26,66 \pm 1,18$ \\
\hline Índice de Iodo $(\mathrm{gI} / 100 \mathrm{~g})$ & $100,00 \pm 0,90$ & $95,10 \pm 0,20$ \\
\hline Teor de Umidade $(\mathrm{mg} / \mathrm{kg})$ & $518,00 \pm 1,62$ & $210,00 \pm 1,46$ \\
\hline Índice de Saponificação $(\mathrm{mg} \mathrm{KOH} / \mathrm{g})$ & $181,46 \pm 0,23$ & $170,10 \pm 1,15$ \\
\hline
\end{tabular}

O óleo de peixe estudado apresentou um índice de acidez de 10,86 bem acima do encontrado na literatura: 2,81 mg KOH/g (SANTOS et al., 2010); 1,47 mg KOH/g (BERY et al., 2012); 5,8 mg KOH/g (OLIVEIRA et al., 2013). O valor recomentado por Dorado et al.(2002) é de no máximo 3\%, para que a transesterificação alcalina seja eficiente. Óleos ácidos em reação de transesterificação alcalina produzem sabão, reduzindo o rendimento da reação e dificultando a separação da glicerina nos ésteres etílicos, assim realizou-se um processo de neutralização do óleo de peixe, tornando-o viável para a produção de biodiesel por transesterificação alcalina deste óleo.

As massas específicas do óleo de peixe a $20^{\circ} \mathrm{C}$, antes e após a neutralização, foram, similares à obtidas por Santos et al. (2010), $911 \mathrm{~kg} / \mathrm{m}^{3}$ a $25^{\circ} \mathrm{C}$ e Bery et al. (2012), $919 \mathrm{~kg} / \mathrm{m}^{3}$ a $20^{\circ} \mathrm{C}$. Foram próximas à massa específica encontrada para o óleo de soja a $20^{\circ} \mathrm{C}$, de acordo com Gomes et al. (2011). Como o óleo de peixe estudado neste trabalho é rico em ácidos graxos de cadeias longas a sua massa especifica é alta. As viscosidades cinemáticas a $40{ }^{\circ} \mathrm{C}$ do óleo de peixe foram próximas às encontrados para o óleo de peixe por Santos et al. (2010), $32,1 \mathrm{~mm}^{2} / \mathrm{s}$ a $37{ }^{\circ} \mathrm{C}$ e Bery et al. (2012), $32 \mathrm{~mm}^{2} / \mathrm{s}$ a $40{ }^{\circ} \mathrm{C}$ e próximas à viscosidade do óleo de soja, Gomes et al. (2011). O índice de iodo se relaciona com a estabilidade oxidativa do óleo e pode determinar seu grau de insaturação (LÔBO et al., 2009). Para o óleo de peixe, foram obtidos valores próximos aos encontrados por Santos et al. (2010), 88, $1 \mathrm{gI}_{2} / 100 \mathrm{~g}$, Bery et al. (2012), $136 \mathrm{gI}_{2} / 100 \mathrm{~g}$ e Oliveira et al. (2013), 72,35 $\mathrm{gI}_{2} / 100 \mathrm{~g}$.

Os teores de umidade do óleo de peixe foram próximos aos encontrados por Santos et al. (2010), $300 \mathrm{mg} / \mathrm{kg}$, Bery et al. (2012), $181 \mathrm{mg} / \mathrm{kg}$ e Oliveira et al. (2013), $120 \mathrm{mg} / \mathrm{kg}$. A transesterificação alcalina não é prejudicada por esse teor de umidade, de acordo Freedman et al. (1984), o limite de umidade é de até $3000 \mathrm{mg} / \mathrm{kg}$. O índice de saponificação estabelece o grau de estabilidade do óleo, em que valores elevados indicam a redução da massa molar, devido a sua deterioração do óleo. Os valores obtidos para o óleo de peixe foram próximos aos encontrados pela literatura por Santos et al. (2010), $193 \mathrm{mg} \mathrm{KOH} / \mathrm{g}$; Bery et al., (2012), $180 \mathrm{mg} \mathrm{KOH} / \mathrm{g}$ e Oliveira et al. (2013), 177,8 mg KOH/g. Esses resultados não interferiram na reação de transesterificação alcalina.

Foi determinada ainda, a composição em ácidos graxos do óleo por cromatografia gasosa. Os valores obtidos, antes e depois da neutralização, estão em acordo com os determinados por Moura et al. (2006) e estão apresentados na Tabela 2. 
Tabela 2 - Composição dos ácidos graxos do óleo de peixe.

\begin{tabular}{lccc}
\hline Ácidos graxos & \multicolumn{3}{c}{ Composição (\%) (Média \pm desvio padrão) } \\
\cline { 2 - 4 } & Óleo de peixe & Após neutralização & $\begin{array}{c}\text { Óleo de peixe } \\
\text { (MOURA et al., 2006) }\end{array}$ \\
\hline Mirístico (C14:0) & $7,67 \pm 0,10$ & $7,61 \pm 0,30$ & 7,06 \\
Palmítico (C16:0) & $21,52 \pm 0,41$ & $22,13 \pm 0,15$ & 17,98 \\
Palmitoléico (C16:1) & $5,81 \pm 0,32$ & $6,18 \pm 0,27$ & 7,55 \\
Estearico (C18:0) & $4,59 \pm 0,09$ & $4,69 \pm 0,32$ & 5,25 \\
Oleico (C18:1) & $8,08 \pm 0,53$ & $8,93 \pm 0,13$ & 13,53 \\
Linoléico (C18:2) & $5,25 \pm 0,22$ & $4,28 \pm 0,10$ & 2,37 \\
Linolaídico (C18:2n-6t) & $2,64 \pm 0,30$ & $1,82 \pm 0,22$ & - \\
Linolênico (C18:3) & $2,43 \pm 0,67$ & $2,44 \pm 0,10$ & 1,13 \\
Araquídico (C20:0) & $3,02 \pm 0,61$ & $3,03 \pm 0,40$ & 0,46 \\
Eicosatrienóico (C20:3n-3) & $2,09 \pm 0,20$ & $2,02 \pm 0,45$ & 0,87 \\
Eicosapentaenóico (EPA) (C20:5) & $13,42 \pm 0,11$ & $13,59 \pm 0,21$ & 14,80 \\
Lignocérico (C24:0) & $1,68 \pm 0,13$ & $1,08 \pm 0,29$ & - \\
Docosahexaenóico (DHA) (C22:6) & $21,80 \pm 0,20$ & $22,20 \pm 0,11$ & 18,15 \\
Ácidos Graxos Saturados & $\mathbf{3 8 , 4 8}$ & $\mathbf{3 8 , 5 4}$ & $\mathbf{3 3 , 1 8}$ \\
Ácidos Graxos Monoinsaturados & $\mathbf{1 3 , 8 9}$ & $\mathbf{1 5 , 1 1}$ & $\mathbf{2 3 , 4 3}$ \\
Ácidos Graxos Insaturados & $\mathbf{4 7 , 6 3}$ & $\mathbf{4 6 , 3 5}$ & $\mathbf{4 3 , 3 8}$ \\
\hline
\end{tabular}

Os ácidos graxos saturados, monoinsaturados e poli-insaturados predominantes foram, respectivamente, o palmítico, o oleico e o docosaexaenoico, similares aos encontrados por Moura et al. (2006). As percentagens de ácidos graxos insaturados encontradas foram elevadas, sendo o óleo, predominantemente, composto pelos ácidos docosahexaenóico (DHA) (C22:6), palmítico (C16:0), eicosapentaenóico (EPA) (C20:5), oleico (C18:1) e mirístico (C14:0), diferente da composição química do óleo de soja, o mais utilizado na produção de biodiesel, que de acordo com Gomes et al. (2011), é composto, principalmente, dos ácidos linoleico (C18:2), oleico (C18:1) e palmítico (C16:0). O óleo de peixe possui alto índice de ácidos graxos insaturados, e de acordo com Knothe et al. (2006), óleos com alto teor de ácidos graxos insaturados proporcionarem uma elevada fluidez ao biodiesel, sendo uma característica positiva para o óleo de peixe.

A massa molar média do óleo de peixe que foi $893,36 \pm 0,15 \mathrm{~g} / \mathrm{mol}$ e após a neutralização $891,97 \pm 0,33 \mathrm{~g} / \mathrm{mol}$. As massas molares médias do óleo de peixe, antes e depois da neutralização, estão próximas às apresentadas por Santos et al. (2010), $903 \mathrm{~g} / \mathrm{mol} \mathrm{e}$ Oliveira et al. (2013), 929,36 g/mol em óleos de peixe.

\subsection{Análise de Controle de Qualidade do Biodiesel}

O índice de acidez obtido nos ésteres etílicos formados por meio do óleo de peixe foram semelhantes aos obtidos por Martins et al. (2015) e Hong et al (2013) e considerado dentro das especificações da ANP, conforme mostrado na Tabela 3. A presença de impurezas acarretam mudanças na densidade do biodiesel (LÔBO et al., 2009), a massa específica do biodiesel foi dentro do limite especificado pela ANP e próxima aos valores encontrados por Martins et al. (2015), Hong et al. (2013) e Yahyaee et al. (2013) em ésteres etílicos a partir do óleo de peixe. 
Tabela 3 - Características físico-químicas dos ésteres etílicos produzidos a partir do óleo de peixe.

\begin{tabular}{|c|c|c|}
\hline Parâmetros & Limite ANP & Éster Etílico (Média \pm desvio padrão) \\
\hline \hline Índice de Acidez $(\mathrm{mg} \mathrm{KOH} / \mathrm{g})$ & Máx. 0,50 & $0,32 \pm 0,08$ \\
\hline Massa Específica $20^{\circ} \mathrm{C}\left(\mathrm{kg} \cdot \mathrm{m}^{3}\right)$ & 850 a 900 & $885 \pm 0,09$ \\
\hline Viscosidade $40^{\circ} \mathrm{C}\left(\mathrm{mm}^{2} / \mathrm{s}\right)$ & 3,0 a 6,0 & $4,62 \pm 0,08$ \\
\hline Teor de Umidade $(\mathrm{mg} / \mathrm{kg})$ & Máx. 200,0 & $119 \pm 0,91$ \\
\hline Glicerol livre $(\%$ massa) & Máx. 0,02 & $0,015 \pm 0,006$ \\
\hline Teor de Ésteres (\%massa) & 96,5 & $96,41 \pm 0,22$ \\
\hline
\end{tabular}

O biodiesel apresentou viscosidade dentro do limite especificado pela ANP e similar aos obtidos por Martins et al. (2015), Hong et al. (2013) e Yahyaee et al. (2013). O valor determinado para o teor de umidade do óleo de peixe foi semelhante ao encontrado por Martins et al. (2015) e dentro do estabelecido pela ANP. O valor obtido do teor de glicerol livre nos ésteres etílicos foi dentro do limite estabelecido pela ANP. O teor de éster obtido nesse trabalho foi de $96,41 \pm 0,22 \%$ em massa, próximo à porcentagem estabelecida pela ANP.

\section{CONCLUSÃO}

A partir da caracterização da matéria-prima, observa-se que o óleo de peixe é apto para a produção de biodiesel. O óleo obtido de resíduos do beneficiamento do peixe é um produto de baixo valor agregado, tendo como principal vantagem na sua utilização a possível redução do preço de produção do biodiesel devido à redução de gastos com a matéria-prima. $\mathrm{O}$ óleo de peixe é rico em ácidos graxos de cadeia longa, assim apresenta uma excelente conversão em ésteres etílicos, com teor de éster de 96,41\% $\pm 0,22$, dentro do limite estabelecido pela ANP, de no mínimo 96,5\% em massa para ser considerado como biodiesel.

\section{REFERÊNCIAS}

ANP - Agência Nacional do Petróleo, Gás Natural e Biocombustíveis. Biodiesel, 2016. Disponível em: < http://www.anp.gov.br/wwwanp/biocombustiveis/biodiesel>. Acesso em 20 jan. 2017.

A.O.A.C. - Association of Official Analytical Chemists. Official methods of analysis of AOAC International. Food composition, additives, natural contaminants. 16. ed. v. 2. Gaithersburg: AOAC, 1997.

A.O.C.S. - American Oil Chemists' Society. Official methods and recommended practices of the American Oil Chemists' Society. Champaing, Ill.: AOCS, 2004.

BERY, C. C. S.; NUNES, M. L.; SILVA, G. F.; SANTOS, J. A. B.; BERY, C. S. ESTUDO DA VIABILIDADE DO ÓLEO DE VÍSCERAS DE PEIXES MARINHOS (Seriola Dumerlii (ARABAIANA), Thunnus ssp (ATUM), Scomberomorus cavala (CAVALA) e Carcharrhinus spp (CAÇÃO)) COMERCIALIZADOS EM ARACAJU-SE PARA A PRODUÇÃO DE BIODIESEL. R. Geintec, v. 2, n. 3, p.297-306, 2012.

DANTAS, M. B. Obtenção, caracterização e estudo termoanalítico de biodiesel de milho. 2006. Dissertação (Mestrado em Química - Centro de Ciências Exatas e da Natureza, Universidade Federal da Paraíba, João Pessoa, 2006. 
DORADO, M.P., BALLESTERO, E., DE ALMEIDA, J.A., SCHELLERT, C., LÖHRLEIN, H.P., KRAUSE, R. An alkalai-catalyzed transesterification process for high free fatty acid waste oils. Trans. Amer. Soc. Agricul. Eng.., v.45, n. 3, p. 525-529, Maio, 2002.

FREEDMAN, B.; PRYDE, E. H.; MOUNTS, T. L. Variables affecting the yields of fatty esters from transesterified vegetable oils. J. Amer. Oil Chemists' Soc., v. 61, n. 10, p. 1638-1643, 1984.

GERIS, R.; SANTOS, N. A. C.; AMARAL, B. A.; MAIA, I. S.; CASTRO, V. D.; CARVALHO, J. R. M. Biodiesel de soja: reação de transesterificação para aulas práticas de química orgânica. Quí. Nova, v.30, n.5, p.1369-1373, 2007.

GOMES, M. C. S.; ARROYO, P. A.; PEREIRA, N. C. Biodiesel Production From Degummed Soybean Oil and Glycerol Removal Using Ceramic Membrane. J. Membr. Science 378 - 453 - 461. May. 2011.

HONG I. K.; PARK, J. W.; LEE,S. B. Optimization of fish-oil-based biodiesel synthesis. Journal of Industrial and Engineering Chemistry, v.19, p. 764-768, 2013.

KNOTHE, G; KRAHL, J.; GERPEN, J. V.; RAMOS, L. P. Manual do biodiesel. São Paulo: Blucher, 2006.

LÔBO, I. P.; FERREIRA, S. L. C.; CRUZ, R. S. Biodiesel: parâmetros de qualidade e métodos analíticos. Quí. Nova. v.32, n.6, p. 1596-1608, 2009.

MARTINS, G. I.; SECCO, D.; ROSA, H. A.; BARICCATTI, R. A.; DOLCI, B. D.; SOUZA,S. N. M.; SANTOS, R. F.; SILVA, T. R. B. GURGACZ, F. Physical and chemical properties of fish oil biodiesel produced in Brazil. Renew. and Sustainable Energy R., v. 42, p. 154-157, 2015.

MOURA J. M. L. N.; GONÇALVES L. A. G.; GRIMALD R.; SOARES S. M.; RIBEIRO A. P. B. Otimização das condições de produção de ésteres etílicos a partir de óleo de peixe com elevado teor de ácidos graxos w-3. Química Nova. v.29 n.5, Set./Out. 2006.

OLIVEIRA L. E.; BARBOZA J. C. S.; DA SILVA M. L. C. P. Production of ethylic biodiesel from Tilápia visceral oil. Renew. Energy and Power Quality J. , v. 13, p. 412, 2013.

ONU - Organização das Nações Unidas para a Alimentação e a Agricultura. 2016. Disponível em: < http://www.fao.org/brasil/noticias/detail-events/pt/c/423722/>. Acesso em 20 jan. 2017.

SANTOS, F. F.P.; MALVEIRA, J. Q.; CRUZ, M. G.A.; FERNANDES, F. A.N. Production of biodiesel by ultrasound assisted esterification of Oreochromis niloticus oil. Fuel, v.89, p. 275-279, 2010.

YAHYAEE, R.; GHOBADIAN, B.; NAJAFI, G. Waste fish oil biodiesel as a source of renewable fuel in Iran. Renewable and Sustainable Energy Reviews, v.17, p.312-319, 2013.

ZUMACH, F. C.; SIMONELLI, G.; STINGUEL, L.; MOTTA, V. C. N. Determinação das variáveis que afetam a neutralização do óleo de pinhão manso. Enciclopédia Biosfera , v.8, p. 2257-2266, 2012. 